\title{
The effects of pbl-based data science education program using app inventor on elementary students' computational thinking and creativity improvement
}

\author{
Yong Min Kim, Jeju City Office of Education, Jeju, Korea, mega11@korea.kr
}

\begin{abstract}
This study is to investigate the effect of PBL-based Data Science Education Program using App Inventor on Computational Thinking and Creativity of elementary students. Based on the results of the pre-requisite analysis by Rossett's demand analysis model, PBL-based Data Science Education program was designed according to the procedure of 'ADDIE model' which is 42 hours of classroom instruction for elementary student. As a result of the Paired t-test, it was proved that the Computational Thinking was statistically significantly improved in the post-test. In addition, as a result of the Paired t-test and Wilcoxon's signed rank test, it was found that the sub-factors of Creativity were 'Originality', 'Elavoration', 'Closure', 'Average', and 'Index'. Therefore, it was confirmed that the PBL-based Data Science Education Program using App Inventor is effective in improving Computational Thinking and Creativity of elementary student.
\end{abstract}

Keywords: PBL, App Inventor, Data Science, Computational Thinking, Creativity

Received: $15.11 .2020 \quad$ Accepted: 11.12.2020 Published: 16.01 .2021

\section{INTRODUCTION}

In keeping with the social changes caused by the '4IR(fourth industrial revolution)', represented by artificial intelligence and big data, the 'Ministry of Education' suggested future core competencies in order to cultivate the competencies required by the future society at school. In particular, the '2015 Revised Curriculum' emphasizes Computational Thinking as a core competency for creative fusion talent. Accordingly, in order to reinforce Computational Thinking that can creatively and cooperatively solve various problems in real life through information curriculum, software education is obligated in elementary and middle schools.

Software education in elementary and middle schools aims to develop real-life problem-solving capabilities through Computational Thinking. According to 'Wing', Computational Thinking is to think like a computer scientist when encountering a problem to be solved, to establish a problem, to logically organize and analyze data to solve a problem (Wing, 2006).

In particular, in the era of the '4IR', education must cultivate the ability to extract useful information by collecting and analyzing necessary data among numerous digital data, Data Science Education can cultivate such abilities.

Creativity is also a major area of interest that many scholars are interested in to improve through software education along with Computational Thinking.

Companies such as 'Google', 'Amazon', and 'Netflix', which are enjoying the best competitiveness through big data analysis, have in common that they are the most creative companies in the world. The fact that the world's most creative companies are gaining competitive advantage based on data analysis suggests two things (Kim, 2020). First, in the era of big data, the source of corporate creativity lies in the analysis of data, and the second is that individual creativity can also be cultivated through efforts to increase analysis capability (Kim, 2020).

Yun et al. (2019)'s study, it was proved that through a media art convergence talent education program that utilizes Data Science and artificial intelligence, it is possible to improve creativity through Data Science Education by promoting convergent thinking and creativity.

PBL (Project Based Learning) is a learning method in which learners make plans for solving a project on their own, find data, and collaborate on solutions to share results. PBL is effective in improving problem solving ability, it is widely used in programming education.

In general, the process of solving a problem in data science education consists of the process of defining (searching) a problem by the learner himself, collecting and analyzing data, and generalizing (statistical reasoning) to predict a phenomenon. In this process, more in-depth exploration can be made in the process of solving data problems when PBL is based. 


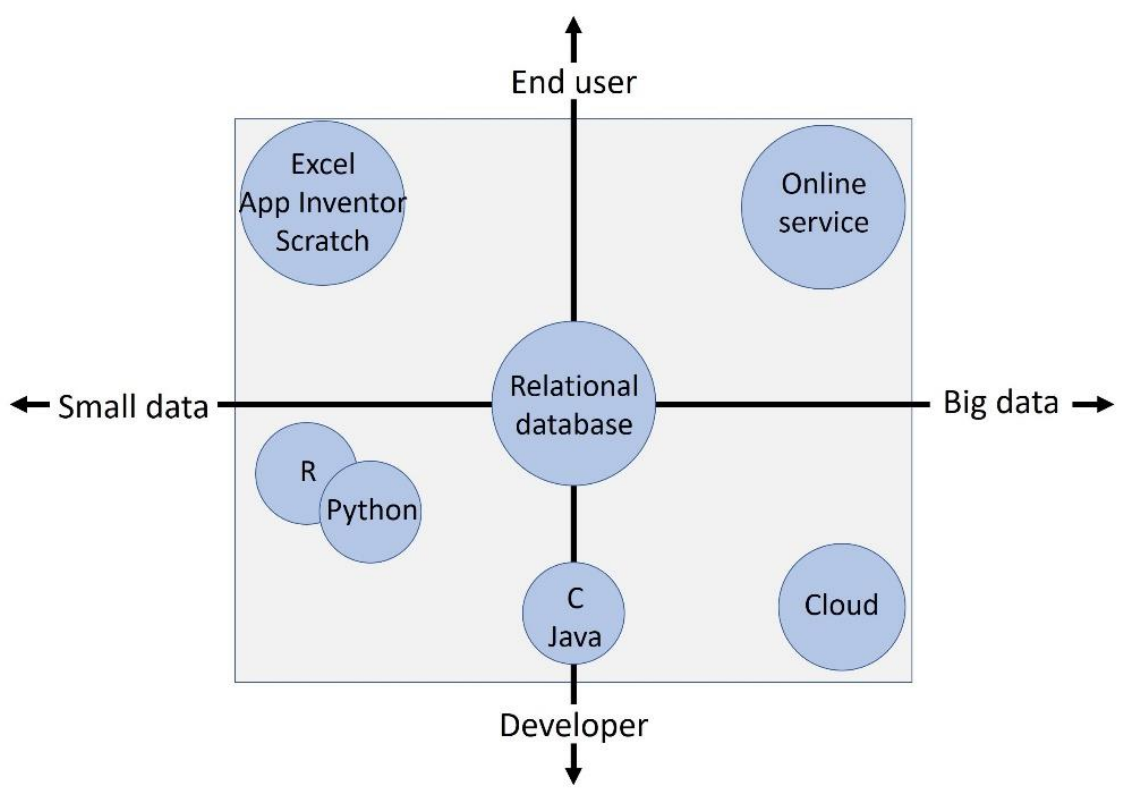

Figure 1. Data Science Education tool

On the other hand, tool selection is a part that depends on the work environment and data. According to Figure 1, tools aimed at elementary students and beginners should be easy to use and simple to use, such as 'Excel' and 'App Inventor', and can be used with relatively little programming experience.

Statistics packages such as 'Excel' and ' $\mathrm{R}$ ' are widely used as data collection and analysis tools, but it is difficult to find a case where only statistical packages are used instead of programming languages for the entire process of solving Data Science problems.

Accordingly, 'Python' is being used a lot these days. In the case of 'Python', in steps such as data visualization, deep learning, and machine learning, open source software libraries such as' TensorFlow' and 'Keras' must be installed and utilized. Therefore, for beginners such as elementary students who are not data scientists, it is not easy to use statistics packages such as 'Excel' and 'R' or 'Python'.

However, according to the recent development of various mobile devices, 'App Inventor', which is widely used for app production in educational fields, is an educational programming language that is not difficult to use even for beginners. In addition, it is suitable as a data visualization tool because it is possible to implement a bar graph of the collected data by learning a simple command block.

Therefore, in this study, we attempt to verify the effect of using 'App Inventor' as a Data Science Education tool to find out 'The effect of PBL-based Data Science Education Programs on elementary students' Computational Thinking and creativity'.

\section{THEORETICAL BACKGROUND}

\section{PBL}

PBL(Project Based Learning) refers to learning in which learners determine solutions to be explored and achieve cognitive, affective and psychological goals in the process of designing, implementing and presenting solutions, discussions and debate, and persuasion (Chae, 2017). PBL basically includes a cooperative learning process with a clear goal and reflection, emphasizing high-level thinking skills such as problem-solving, decision-making, and reflective thinking, and is a process of autonomously writing the outcome of learning tasks through active participation of learners (Lee, 2013). In keeping with the social changes caused by the '4IR(fourth industrial revolution)', represented by artificial intelligence and big data, the 'Ministry of Education' suggested future core competencies in order to cultivate the competencies.

\section{App Inventor}

App Inventor was changed from Google to MIT App Inventor in 2010, and can be used in a web browser, so it is widely used for education. App Inventor's app creation environment was designed to be optimized for 'Java' and 'Chrome browsers' (Rim, 2013). App Inventor is an object-oriented language and is suitable for use as an educational programming language and allows students to solve problems on their own. In addition, it can be easily accessed by anyone and it does not take much time and effort to learn, so it can greatly reduce the psychological burden of learners. 


\section{Data Science}

It is known that the term Data Science was first used by Cleveland in 2001, and according to the NCDS(National Consortium for Data Science), Data Science is a field of scientific observation, theory development, systemic analysis, hypothesis experimentation, and verification of digital data.

The vast amount of data we have encountered in recent years needs to be properly collected and analyzed as needed, but traditional methods cannot handle the overflowing data. One of the disciplines that collects, analyzes, and processes such data is Data Science, which is defined as the convergence of various disciplines such as 'mathematics', 'statistics', 'business administration', 'computer science', and 'library information' (Shi et al., 2014).

Based on 'statistics', 'computer science', and 'management engineering', Data Science covers the entire process from data structure and collection to analysis and storage based on 'data mining', 'management science', and 'management informatics'. Data Science has a great influence on data management in various fields such as 'bioinformatics', 'library and information science', and 'management of technology'.

\section{Computational Thinking}

The term 'Computational Thinking' was first used in 1980 by 'Seymour Papert', a mathematician, computer scientist, educator, and creator of the programming language 'Logo', a contributor to the field of artificial intelligence, and began to be known in earnest by 'Wing'.

'Wing' defined 'Computational Thinking' as 'basic thinking ability that all people who will live in the future knowledge and information age must have an abstract thinking ability that includes basic concepts of computer science, problem solving methods and system design methods based on computer science principles, and understanding of human behavior'(Wing, 2006).

According to the '2015 Revised Curriculum', Computational Thinking refers to the ability to understand problems in real life and various academic fields by using the basic concepts and principles of computer science and computers, and to find and apply solutions creatively. It is known to include creative fusion skills.

Computational Thinking can be said to be the central concept of computer science, and many advanced countries recognize its importance and continue to conduct research to include it in the regular curriculum. Recently, active academic research has been conducted on computing thinking skills in Korea.

\section{Creativity}

Since 'Creativity' is known to be the highest level of performance and achievement of human beings, it is difficult to define the concept of 'Creativity' in a single word, and there are different opinions on the definition of 'Creativity' according to researchers.

'Osborn' defined it as a universal ability that everyone has, and 'Maslow' divided it into 'special talent' and 'self-realization' creativity. 'Guilford' divided into convergent thinking and divergent thinking. 'Torrance' defined new and unique ideas, different perspectives, and problems in a new light (Jeon, 2006).

\section{Analysis of prior research}

Shin et al. (2015)'s study, the limitations of the existing STEAM program were analyzed, and the STEAM program using App Inventor was developed and presented.

Kim \& Yoo (2017)'s study, as a result of developing and applying a software education program using App Inventor for the purpose of developing Computational Thinking for elementary students, it was found that the learners' Computational Thinking was improved and computer-related attitudes also showed positive changes.

Kim \& Lee (2018)'s study, a self-directed learning centered on learner participation was designed by incorporating the Jewish Habruta education method into the creation of an app that attracts learners' interest. Through this, it was intended to enhance Computational Thinking, which is an essential competency in the era of the ' $4 \mathrm{IR}^{\mathrm{\prime}}$ ', and to cultivate creative fusion-type talents with the right personality.

Kim \& Song (2017)'s study, based on PBL, a methodology already applied to several subjects, and App Inventor, one of the good tools for software education, an educational program suitable for the '2015 Revised Curriculum' was designed.

Until now, many studies using scratch among physical computing and educational programming languages have been conducted, and are widely applied in the field of software education leading schools. However, looking at previous studies, it can be seen that few studies have verified the improvement of Computational Thinking and Creativity by applying App Inventor to educational activities. In addition, there are no studies on PBL-based data science education or studies that verify the improvement of 
learners' Computational Thinking and Creativity by using educational programming languages for Data Science Education.

The software education methodology to date has remained mostly in physical computing or field application and effectiveness verification for some educational programming languages. Therefore, it is considered necessary to study whether the development and application of data science education programs can actually improve learners' Computational Thinking and Creativity as one of several alternatives to this.

\section{METHODS}

ISD(Instructional System Development) model basically applied the 'ADDIE model', and for the analysis of learner needs, Rossett's needs analysis model was used. The details of research and research methods according to the stages of the 'ADDIE model' are as follows.

Analysis:

A study on Computational Thinking and Creativity (literature study)

Prior research analysis (case study)

Analysis of learners' needs (research study)

Design:

Development of tools to be used for evaluation (literature research)

Development:

Development of strategies required for teaching (research/literature research)

PBL-based Data Science Education program development (development research)

Implementation:

Evaluation:

PBL-based Data Science Education program applied (experimental research)

Analysis of educational program application results (experimental research)

\section{Data Science Education Program Development Practices and Applications}

The program development model is the 'ADDIE model', and the 'ADDIE model' is a representative model of instructional design that focuses on the process, and the 'analysis' stage is the initial stage of instructional design, which is a stage to analyze the elements of absolute importance in the design situation. The 'design' stage is a stage to creatively synthesize the outputs from the analysis stage. The 'development' stage is the stage of actually developing and producing teaching-learning materials to be used in class. In the 'implementation' stage, the teaching-learning materials and various media completed in the development stage are used in the actual field. The 'evaluation' stage is the process of determining whether the final product has fulfilled its intended purpose (Kang, 2011).

\section{Analysis}

A needs analysis was conducted for 205 students in the 4th to 6th grades of elementary school. Figure 2 shows that the experience and interest in educational programming languages is the highest, and it was analyzed that the use of educational programming languages for PBL-based Data Science Education programs would be highly effective.

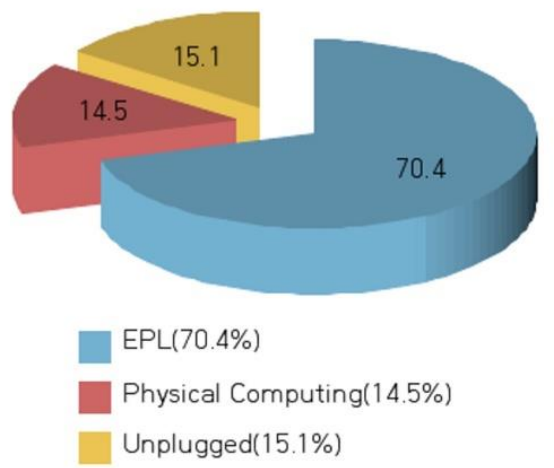

Figure 2. Experience participating in software education

PBL emphasizes cooperative learning activities, problem-solving activities, activities that collect and analyze data to create results, learner-centered autonomous activities, and learner reflection processes for 
the development of high-level thinking skills(Koo, 2018), so the Data Science Education of this study It is a learning method suitable for the program. In to Figure 3, project learning by team is the preferred learning method in the PBL-based Data Science Education program, so it was analyzed that designing an education program taking this into account was necessary.

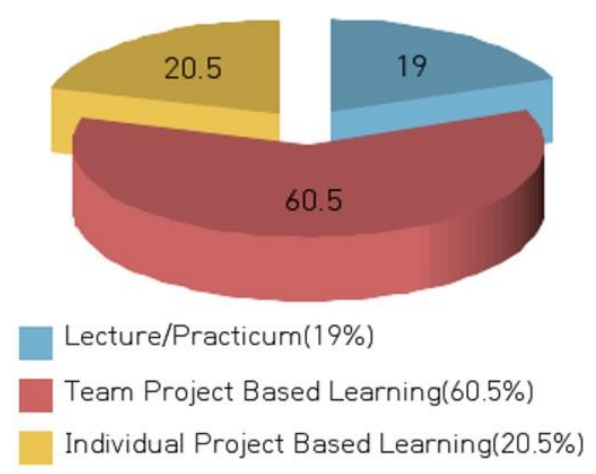

Figure 3. Data science education learning method

According to Figure 4, it is expected that Computational Thinking and Creativity will increase through the PBL-based Data Science Education program.

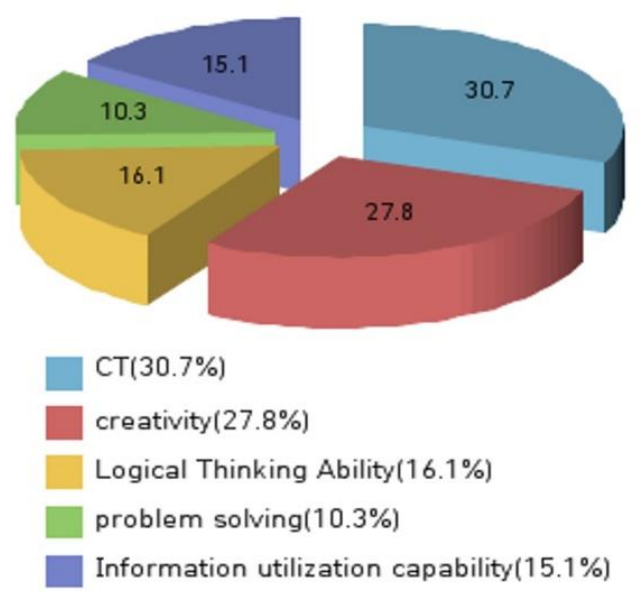

Figure 4. Improve capacity through data science education

\section{Design}

PBL-based Data Science Education program tools for elementary students should be easy to use, simple to use, and able to use with relatively little programming experience. App Inventor is used in this study because it can be easily accessed by anyone, and it takes less time and effort to learn grammar as well as practical experience, so it can relieve the psychological burden.

The data-based problem solving steps were organized as shown in Figure 5 after the researcher arranged the problem solving steps of Kim (2016)'s 


\begin{tabular}{|c|c|}
\hline Define data problem (problem searching) & $\begin{array}{c}\text {.Define the problem } \\
\text {.Define data } \\
\text {.Define research questions and hypotheses }\end{array}$ \\
\hline & $\Downarrow$ \\
\hline Data collection & $\begin{array}{l}\text { Determine the collection method } \\
\text {.Check the quality of data } \\
\text {.Prepare the data } \\
\text {.Add, select, and edit data }\end{array}$ \\
\hline \multirow[b]{2}{*}{$\begin{array}{l}\text { Understanding phenomena: Exploratory } \\
\text { data analysis }\end{array}$} & $\Downarrow$ \\
\hline & $\begin{array}{l}\text { Visualize by looking at the original data } \\
\text {.Analyze individual properties } \\
\text {.Analyze relationships between attributes }\end{array}$ \\
\hline \multirow{3}{*}{ Generalize the phenomenon } & $\Downarrow$ \\
\hline & Statistical inference \\
\hline & $\Downarrow$ \\
\hline \multirow[t]{2}{*}{ Predicting phenomena } & Machine learning \\
\hline & $\Downarrow$ \\
\hline Data Story Telling & .Presentation, sharing \\
\hline
\end{tabular}

Figure 5. General procedure for problem-solving based on data

\section{Development \& Implementation}

For a total of 6 days, 42 times were conducted for 26 elementary students who applied for the educational donation program conducted by Jeju National University. According to the needs analysis result and the characteristics of the Data Science Education tool, educational content was selected as shown in Table 1 and an education program was developed. A part of the program of 'Collecting Data to Establish a School Trip Plan', the project learning topic of the 8 14 times, is shown in Figure 6.

Table 1. The theme of Data science education program

\begin{tabular}{|l|l|}
\hline Hour & Learning theme \\
\hline $\mathbf{1} \sim \mathbf{7}$ & $\begin{array}{l}\text { Understand the meaning of data science, learning the basic functions of App } \\
\text { Inventor for that }\end{array}$ \\
\hline $\mathbf{8 \sim 1 4}$ & Automatically collect data and make an experiential learning plan \\
\hline $\mathbf{1 5 \sim 2 1}$ & $\begin{array}{l}\text { Detect vibrations, create applications to gather their data, practice living } \\
\text { handling earthquakes }\end{array}$ \\
\hline $\mathbf{2 2 \sim 2 8}$ & $\begin{array}{l}\text { Collect their data, examine the influence of habits on health Think about } \\
\text { desirable lifestyle }\end{array}$ \\
\hline 29 35 & $\begin{array}{l}\text { Think about the points you usually cared about, decide the theme, collect your } \\
\text { data and solve it }\end{array}$ \\
\hline $\mathbf{3 5 \sim 4 2}$ & $\begin{array}{l}\text { After giving feedback on the final report, make final announcement through } \\
\text { correction and replenishment(data story telling) }\end{array}$ \\
\hline
\end{tabular}




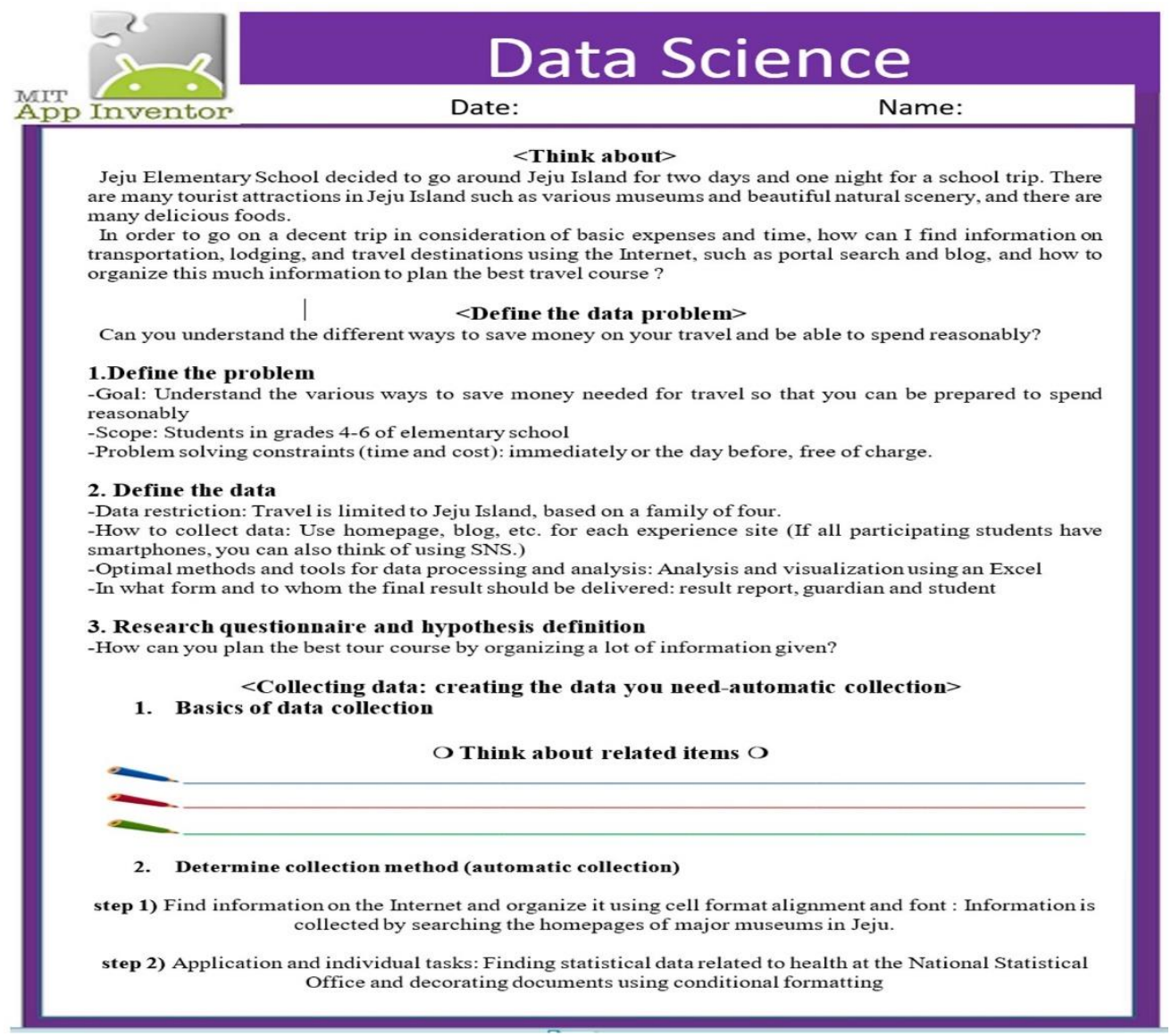

Figure 6. Data science education program

The PBL-based Data Science Education program developed in this study was applied to a total of 42 times during classes held for 6 days in the form of an intensive course during vacation to control external variables in schools and academies. Classes were held every day from 9 am to $15 \mathrm{pm}$, with 7 sessions every 40 minutes. On the last day, the final project report was finished with a final presentation (data storytelling) to all students and parents.

Figure 7 shows the application process according to the data problem solving process for one of the final project reports written by students. The theme is 'Is it related to the average sleep time and height growth of elementary students?'

\begin{tabular}{|c|c|c|c|}
\hline \multicolumn{4}{|c|}{ My Data Science Report } \\
\hline subject & Is it related to average sleep time and height growth of elementary school students? & Submission date & \\
\hline school & OO Elementary School & name & Kim OO \\
\hline \multicolumn{4}{|c|}{$<$ Reason (motive) and content of the topic selection $>$} \\
\hline \multicolumn{4}{|c|}{$\begin{array}{l}\text { There are an increasing number of elementary school students who do not sleep until late, and there were many short children among } \\
\text { them, so I investigated to see if there was any connection. }\end{array}$} \\
\hline \multicolumn{4}{|c|}{$<$ Step-by-step data science analysis $>$} \\
\hline \multicolumn{4}{|c|}{$\bullet$ Step 1-Define the problem $\bullet$} \\
\hline \multicolumn{4}{|c|}{$\begin{array}{l}\text { - Problem: Many of the students who do not sleep until late are short-lived. } \\
\text { - Goal: to find out the relationship between sleep time and height growth } \\
\text { - Hypothesis: Students who do not sleep a lot will be short. }\end{array}$} \\
\hline \multicolumn{4}{|c|}{$\bullet$ Step 2-How to collect data $\bullet$} \\
\hline \multicolumn{4}{|c|}{$\begin{array}{l}\text { 1. Collection method } \\
\text { - Eligibility: Students in grades } 4-6 \text { of elementary school }\end{array}$} \\
\hline \multicolumn{4}{|c|}{ - Method: Google Survey } \\
\hline \multicolumn{4}{|c|}{$<$ Middle omission $>$} \\
\hline
\end{tabular}

Figure 7. Final report (Kim OO). 
First, in the step of 'Defining a data problem (exploring a problem)', the 'problem' (what is the problem or question?), the 'goal' (what do you want to obtain by solving the problem or question?), 'hypothesis' (the problem or question What is the reason I thought about?) as shown in Figure 8.

Problem: Many of the students who do not sleep until late are short-lived.
Goal: to find out the relationship between sleep time and height growth
Hypothesis: Students who sleep less will be short.

Figure 8. Define data problem(problem searching

<Collection method $>$
-Eligibility: Elementary school students
-Method: Google Survey
<Contents of the questionnaire $>$
1. What is your grade level?
1) 4th grade 2) 5th grade 3) 6th grade
2. What is your gender?
1) man 2) woman
3. What is your sleep time per day?
1) 12 hours or more 2) 11 hours 3) 10 hours 4) 9 hours 5) 8 hours 6) 7 hours 7) 6 hours 8) 5 hours or less
4. Please write your own key.

Figure 9. Define data problem (problem searching

In the 'data collection' step, as shown in Figure 9, the data collection method and items for data collection were determined, and data was prepared by directly collecting the data and quantifying those that can be quantified.

The 'Understanding Phenomenon' step is a step to perform exploratory data analysis. As shown in Figure 10, the original data is examined and visualized, individual attributes are analyzed, and relationships between attributes are analyzed.

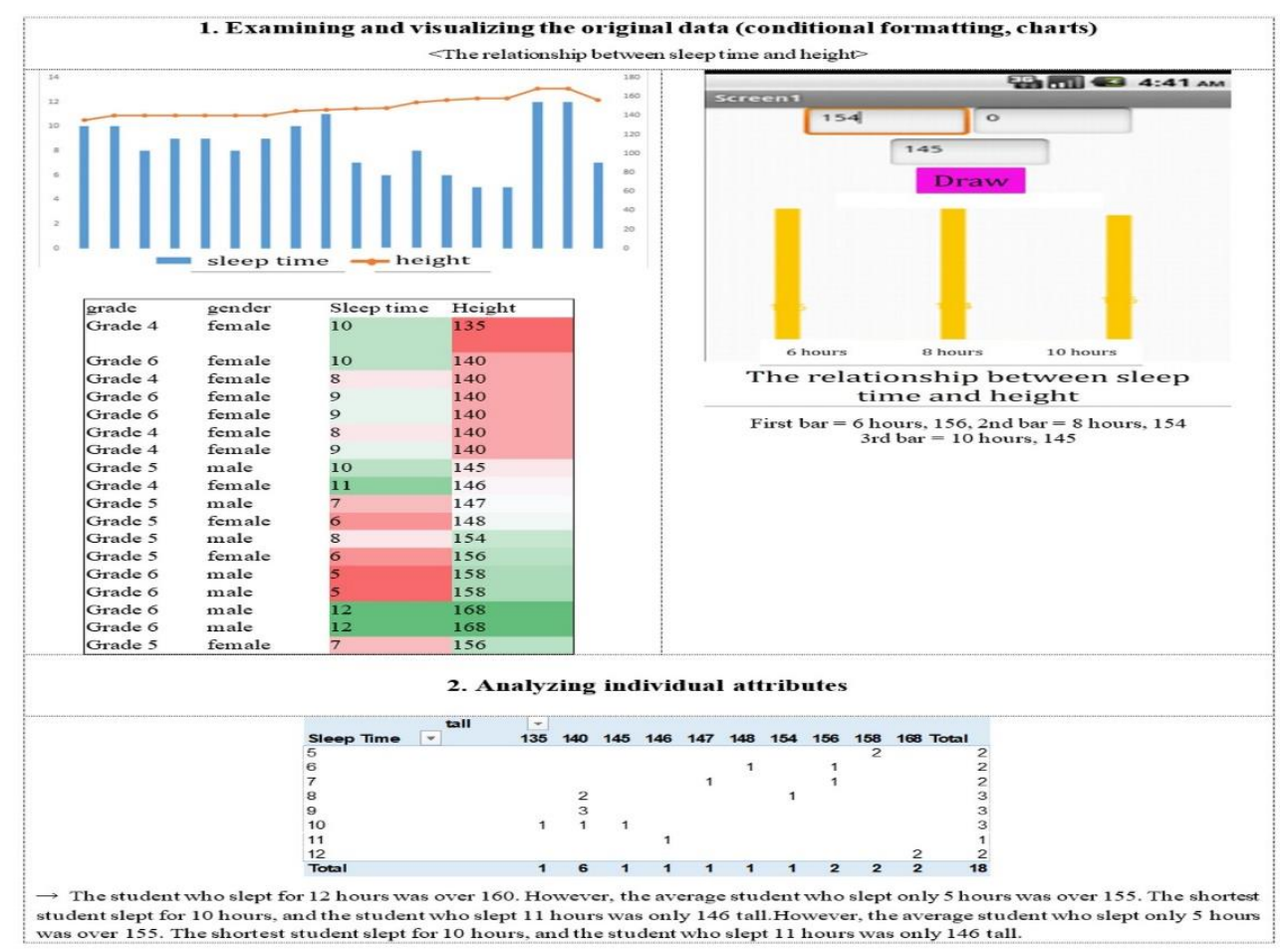

Figure 10. Define data problem (problem searching 
In the 'generalizing phenomena' step, based on the data analyzed as shown in Figure 11, I compared the hypotheses I had made to draw conclusions and make statistical inferences.

Conclusion: Contrary to my hypothesis, looking at the chart above, sleeping time alone does not seem to be related to height growth. I think if you compare your sleep time with your usual diet, exercise, etc., it will have a relationship with height growth.

Statistical Reasoning: Still, it's not completely unrelated to sleep time, so it's better to get a lot of sleep. It's also a good idea to adjust your diet, your regular exercise time, and what you do before bed. Next time, I want to find out why I am not tall.

Figure 11. General procedure for problem-solving based on data

In the 'predicting the phenomenon' stage, the conclusion was confirmed through experimental research, and in order to prevent statistical errors in causal relations, the correlation was checked through confirmation experiments, etc. to make future predictions. The final presentation (data storytelling) was run as a time to present each final project report in front of the students and parents.

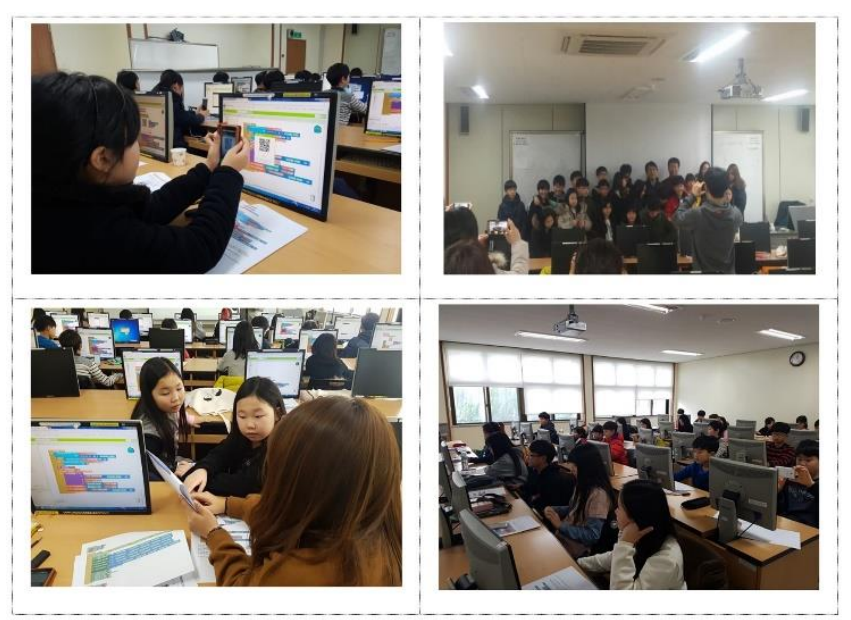

Figure 12. Data storytelling scene

\section{Evaluation}

Table 2 is a verification tool for improving Computational Thinking and Creativity through the application of the PBL-based Data Science Education program developed in this study. Computational Cognition Tests A and B of Byung Soo Kim(2014) were used as a tool 'Computational Thinking', and shapes A and B on the TTCT test paper were used as a tool for testing 'Creativity'.

Table 2. Experimental design

\begin{tabular}{|l|l|l|l|}
\hline & Pre-test & Treatment & Post-test \\
\hline class & $\mathrm{O}_{1}$ & $\mathrm{x}$ & $\mathrm{O}_{2}$ \\
\hline $\mathrm{X}:$ Science education program for personal data utilization data \\
$\mathrm{O}_{1}$ : Pre test(Computational Thinking, creativity) \\
$\Rightarrow$ normality test(Shapiro-Wilks test) \\
$\mathrm{O}_{1}, \mathrm{O}_{2}$ : Pre-Post test(Computational Thinking, creativity) \\
$\Rightarrow$ After the normality test, Paired sample T-test or Wilcoxon's signed rank test \\
\hline
\end{tabular}




\section{RESULTS}

\section{CT(Computational Thinking) change}

First, the 'Shapiro-Wilks test' was performed to confirm whether the experimental group secured normality, and the results were presented in Table 3.

Table 3. Normality test (CT)

\begin{tabular}{|l|l|l|l|l|l|l|}
\hline $\mathbf{N}$ & Mean & Std.Dev. & Max & Min & t value & p value \\
\hline 26 & 12.23 & 3.972 & 17 & 3 & .924 & .056 \\
\hline
\end{tabular}

${ }^{*} \mathrm{p}<.05$

As a result of conducting the 'Shapiro-Wilks test', the significance was '.056', which was higher than the significance level of ' .05 ', confirming the normal distribution. The 'Paired sample T-test' was conducted as shown in Table 4 in order to find out the change in 'CT(Computational Thinking)' as a result of the preand post-test conducted on the experimental group.

Table 4. Paired sample T-test (CT)

\begin{tabular}{|l|l|l|l|l|l|}
\hline Test & N & Mean & Std.Dev. & t value & p value \\
\hline Pre & 26 & 12.23 & 3.972 & & \\
\hline Post & 26 & 13.5 & 3.455 & & $.009 * *$ \\
\hline
\end{tabular}

${ }^{* *} \mathrm{p}<.01$

As a result of the 'Paired sample T-test' in Table 4, the average value of Computational Thinking in the post-test was ' 13.5 ', which was higher than that of the pre-test, and the significance probability was '.009', which was statistically significantly improved at the significance level of ' .01 '. Therefore, it can be seen that the Computational Thinking was improved as a result of the input of the PBL-based Data Science Education program.

\section{Creativity change}

As a result of the preliminary Creativity test, the 'Shapiro-Wilks test' was conducted to confirm whether the experimental group had normality, and the results were presented in Table 5.

Table 5. Normality test (Creativity)

\begin{tabular}{|l|l|l|l|l|l|l|l|}
\hline Subscales & $\mathbf{N}$ & Mean & Std.Dev. & Max & Min & t value & p value \\
\hline Fluency & 26 & 105.84 & 20.356 & 145 & 66 & .954 & 285 \\
\hline Originality & 26 & 109.42 & 20.333 & 150 & 68 & .959 & 367 \\
\hline Titles & 26 & 101.34 & 43.809 & 158 & 0 & 906 & $\mathbf{0 2 1}^{*}$ \\
\hline Elaboration & 26 & 107.88 & 15.079 & 133 & 80 & 959 & 374 \\
\hline Closure & 26 & 67.42 & 33.761 & 115 & 0 & 917 &. $\mathbf{0 3 8}^{*}$ \\
\hline Average & 26 & 98.38 & 20.723 & 139.4 & 44.8 & .972 & .681 \\
\hline Index & 26 & 102.61 & 22.074 & 145.4 & 44.8 & .967 & .554 \\
\hline
\end{tabular}

${ }^{*} \mathrm{p}<.05$

As a result of conducting the 'Shapiro-Wilks test', the significance in the areas of 'Titles' and 'Closure' was '.021' and '.038', respectively, indicating that the normality was not satisfied. The remaining areas showed a higher significance than the significance level of ' .05 ', confirming that they were normally distributed.

In order to find out the change in creativity as a result of the pre-post test conducted on the experimental group, the 'Paired sample T-test' was performed as shown in Table 6. For the 'Titles' and 'Closure', which did not secure normality, the 'Wilcoxon's signed rank test' was conducted as shown in Table 7. 
Table 6. Paired sample T-test (Creativity)

\begin{tabular}{|c|c|c|c|c|c|c|}
\hline Subscales & Test & $\mathbf{N}$ & Mean & Std.Dev. & t value & p value \\
\hline \multirow{2}{*}{ Fluency } & Pre & 26 & 105.84 & 20.356 & \multirow{2}{*}{-1.781} & \multirow{2}{*}{.087} \\
\hline & Post & 26 & 111.84 & 20.586 & & \\
\hline \multirow{2}{*}{ Originality } & Pre & 26 & 109.42 & 20.333 & \multirow{2}{*}{-2.635} & \multirow{2}{*}{$.014^{*}$} \\
\hline & Post & 26 & 119.07 & 19.114 & & \\
\hline \multirow{2}{*}{ Elaboration } & Pre & 26 & 107.88 & 15.079 & \multirow{2}{*}{-8.739} & \multirow{2}{*}{$.000^{* *}$} \\
\hline & Post & 26 & 128.03 & 14.572 & & \\
\hline \multirow{2}{*}{ Average } & Pre & 26 & 98.38 & 20.723 & \multirow{2}{*}{-4.590} & \multirow{2}{*}{$.000^{* *}$} \\
\hline & Post & 26 & 110.57 & 15.151 & & \\
\hline \multirow{2}{*}{ Index } & Pre & 26 & 102.61 & 22.074 & \multirow{2}{*}{-4.502} & \multirow{2}{*}{$.000^{* *}$} \\
\hline & Post & 26 & 115.50 & 15.859 & & \\
\hline
\end{tabular}

${ }^{*} \mathrm{p}<.05,{ }^{* *} \mathrm{p}<.01$

Table 7. Wilcoxon's signed rank test (Creativity)

\begin{tabular}{|l|l|l|l|l|l|l|}
\hline Subscales & Test & N & Mean & Std.Dev. & t value & p value \\
\hline \multirow{2}{*}{ Titles } & Pre & 26 & 101.34 & 43.809 & -1.029 & .303 \\
\cline { 2 - 7 } & Post & 26 & 110.615 & 30.060 & & \\
\hline \multirow{2}{*}{ Closure } & Pre & 26 & 67.420 & 33.761 & -2.416 & $.016 *$ \\
\cline { 2 - 7 } & Post & 26 & 81.000 & 29.640 & & \\
\hline
\end{tabular}

As a result of 'Paired sample T-test' and 'Wilcoxon's signed rank test' in Table 6 and Table 7, the average value of all sub-elements of creativity increased in the post-test, but especially, 'Originality', 'Elavoration', 'Average', 'Index', 'Closure' were statistically significantly improved.

The t statistic value of 'Originality' is '-2.635', the significance probability is '.014', and the t statistic value of 'Closure' is ' -2.416 ', and the significance probability is '.016.' Therefore, at the significance level of '.05', the post-test score was significantly improved when compared with the pre-test score.

In addition, the $t$ statistic value of 'Fluency' is '-8.739', the significance probability is '.000', the $t$ statistic value of 'Average' is '-4.590', the significance probability is '.000', the t statistic value of 'Index' is '4.502', and the significance probability is It turned out to be '.000'. Therefore, at the significance level of '.01', the post-test score was significantly improved when compared with the pre-test score. It can be seen that Creativity has improved as a result of the input of the PBL-based Data Science Education program.

\section{DISCUSSION AND CONCLUSIONS}

In this study, a PBL-based Data Science Education program using App Inventor was developed and applied to improve Computational Thinking and Creativity for elementary students. As a result of the study, the educational program developed in this study was found to be effective in improving the Computational Thinking and Creativity of elementary students. This is thought to be because App Inventor is a tool that can be easily learned and utilized because even beginners can easily combine blocks to create desired apps, and it is suitable for problem solving activities of PBL-based Data Science Education program.

In addition, through the direct activity-centered PBL-based problem-solving learning process, the learner establishes a plan for solving a project on his own and collects, organizes, expresses, and interprets data according to the data problem-solving stage. It is thought that the sub-elements of creativity improved and had a positive effect on the improvement of Computational Thinking and Creativity.

However, in this study, not all processes were conducted only as small group cooperative activities, and some processes including final projects were also conducted as individual activities as needed. Therefore, it is considered that a follow-up study is needed to verify the difference in the effectiveness of a course consisting only of small groups and an educational program that includes individual activities due to the nature of PBL including cooperative learning process and reflection. 
In addition, since the experimental group of this study could not secure a sample group of 30 or more required for correlation studies, there is a limit to generalization through analysis of the correlation of the experimental results, so follow-up studies with multiple participants are considered necessary.

\section{REFERENCES}

Chae, Y. S. (2017). Case study on Game Production Project Class with Project-Based Learning. The Journal of Image and Cultural Contents, 13, 55-69.

Jeon, K. W. (2006). Introduction to creative education: theory \& practice. Seoul: Changjisa.

Kang, E. C. (2011). Introduction to Educational Methods and Educational Engineering. Seoul: Yswpub.

Kim, B. S. (2014). Programming education program based on PPS to improve computational thinking ability. doctoral dissertation. Jeju National University.

Kim, J, H. (2020). Creativity and data analysis. Https://m.blog.naver.com/PostView.nhn?blogId=bizinfo1357\&logNo=220982421959\&proxyRef erer=https:\%2F\%2Fwww.google.com\%2F. Date accessed

Kim, J. S., \& Lee, T. W. (2018). Improving Computational Thinking by creating Apps that combine Havruta. Korea Society of Computer Information Winter Conference Proceedings, 26(1), 223-226.

Kim, J. Y. (2016). Hello Data Science. Seoul: Hanbit Media.

Kim, K. H., \& Yoo, I. H. (2017). Effects of SW Education Using App Inventor on Computational Thinking and Attitude towards Computer of Elementary School Students. Journal of The Korean Assocaition of Information Ecucation, 21(4), 371-380.

Kim, S. B., \& Song, K. S. (2017). Development of Elementary School Education Program of App Inventor Applying Project Based Learning. Korean Assocaition of Computer Education Conference Proceedings, 21(1), 49-52.

Koo, D. H. (2018). The Development of A Micro:bit-Based Creative Computing Education Program. Journal of The Korean Assocaition of Information Ecucation, 22(2), 231-238.

Lee, K. M. (2013). Computer-Aided Education : Development of PBL-Based Computer Application Instruction Model. The Journal of Korean Assocaition of Computer Education, 16(2), 29-37.

Rim, H. K. (2013). Android App Implementation Teaching using App Inventor for Elementary school students. Journal of Korea Multimedia Society, 18(7),1495-1507.

Shin, S. K., Choi, I. S., \& Bae, Y. K. (2015). Development of STEAM Program using App Inventor-Focusing on the Concept of Speed in Elementary Science Education. The Journal of the Korea Contents Association, 15(4), 530-544.

Shi, Y., P. S. Yu., Y. Zhu., \& Y. Tian (2014). Explore New Field of Data Science Under Big Data Era: Preface for ICDS 2014. Procedia Computer Science. 30, 1-3.

Wing, J. M. (2006). Computational Thinking. Communications of the Association for Computing Machinery, 49(3), 33-35.

Youn, J. Y., Kim, Y. M., So, J. H., \& Kim, Y. H. (2019). A Study on the Media Art STEAM Education Program Using Data Science and Artificial Intelligence. The Korean Society of Science \& Art, 37(5), 265-276. 